\title{
Alterations of HLA class I and class II antigen expressions in borderline, invasive and metastatic ovarian cancers
}

\author{
Youn Soo Lee ${ }^{1^{*}}$, Tae Eung Kim ${ }^{2^{*}}$, \\ Byung Kee Kim ${ }^{1}$, Yong Gyu Park ${ }^{3}$, \\ Gyu-Moon $\mathrm{Kim}^{4}$, Sung-Bae $\mathrm{Jee}^{4}$, \\ Ki Sung Ryu ${ }^{2,4}$, In-Kyung Kim ${ }^{5}$ and \\ Jin Woo Kim ${ }^{2,4,6}$ \\ ${ }^{1}$ Department of Clinical Pathology \\ ${ }^{2}$ Department of Obstetrics and Gynecology, \\ Kangnam St. Mary's Hospital \\ ${ }^{3}$ Department of Biostatistics \\ ${ }^{4}$ Molecular Genetic Laboratory, Catholic Research Institutes of \\ Medical Science \\ ${ }^{5}$ Department of Biochemistry, College of Medicine, The Catholic \\ University of Korea, 505 Banpodong, Seochoku, Seoul 137-701, \\ Korea \\ ${ }^{6}$ Corresponding author: Tel, +82-2-590-2389; \\ Fax, +82-2-593-2389; E-mail, jinwoo@cmc.cuk.ac.kr \\ *These authors contributed equally to this work.
}

Accepted 23 November 2001

Abbreviations: $\beta 2 \mathrm{~m}, \beta 2$-microglobulin; $\mathrm{MHC}$, major histocompatibility complex; H\&E, hematoxylin-eosin; mAb, monoclonal antibody; IHS, Immunohistochemical staining; PBS, phosphate-buffered saline; NK, natural killer

\begin{abstract}
In an effort to understand whether HLA class I and II plays any role in the process of tumorigenesis and metastasis, we have immunohistochemically examined expression of HLA class I and II antigen by using the monoclonal antibodies (mAb) L368 (for $\beta 2 \mathrm{~m}$ of HLA class I), HC-10 (for HLA-B, C heavy chains), and LGII-612.14 (for HLA class II heavy chain) in 5 borderline serous malignancy (BSM), 20 serous adenocarcinomas (SA), 15 borderline mucinous malignancy (BMM), and 10 mucinous adenocarcinomas (MA) of human ovary tumor case tissues. In BSM, the distribution and intensity of HLA expressions failed to reach statistical significance. In SA, HLA class I $\beta 2$-microglobulin ( $\beta 2 \mathrm{~m})$, HLA-B, C heavy chains and HLA class II heavy chain antigen expressions were down-regulated. Although expressions of HLA-B, C heavy chains and class II heavy chain were down-regulated in metastatic SA, there were no differences in HLA expression levels between primary and metastatic lesions. In BMM, class II
\end{abstract}

heavy chain expressions were down-regulated. In MA, $\beta 2 m$, HLA-B, C heavy chains and class II heavy chain expressions were also down-regulated. Thus, we could distinguish the reduction or absence of HLA molecule expression was related to malignant potential. Loss of HLA class I and II molecules in invasive ovarian cancers raises the possibility that this could be a factor for tumor cells to retain invasiveness.

Keywords: ovarian cancer, HLA class I, HLA class II, immunohistochemical staining, metastasis

\section{Introduction}

The major histocompatibility complex (MHC) comprises a family of highly polymorphic genes encoding a set of transmembrane proteins that present peptide epitopes to specific antigen receptors on T cells (Howard et al., 1999). These antigens eventually are reduced to small peptides in the endoplasmic reticulum of the cell and transported to the cell membrane together with a particular $\mathrm{MHC}$ allele to interact with a T-cell receptor-CD3 complex (Townsend et al., 1989). Four major categories of genes are involved in this genetically controlled process: HLA class I, HLA class II, proteasome, and transported genes (Garrido et al., 1995). A major characteristic of these genes is their very high degree of HLA polymorphism (Campbell and Trowsdale, 1993). In humans, polymorphism is concentrated mainly in class I and class II genes (Powis et al., 1992).

The down-regulation of all or some HLA alleles in a particular individual by whatever mechanism breaks the polymorphism and abolishes the capacity to present antigens through $\mathrm{MHC}$ products. Cell transformation is associated in many cases with $\mathrm{MHC}$ down-regulation (Schrier et al., 1983). Altered HLA phenotypes could arise during any of different steps in the biosynthetic pathway leading to HLA membrane expression, i.e. transcriptionregulation defects, overexpression of protooncogene products, loss of transporter molecules, mutations in or loss of $\beta 2 \mathrm{~m}$ gene or HLA genes, and loss of HLA haplotypes secondary to loss of heterozygosity (Browning and Dunnion, 1997; Garrido et al., 1997; Koopman et al., 1998).

The expression of MHC class I antigens is altered in a large variety of malignant tumors derived from different tissue types (Redondo et al., 1997). Factors that may contribute to HLA down-regulation in ovarian cancer are not well understood. Although HLA class I down-regu- 
lation including $\beta 2 m$ and HLA-A2 was observed in ovarian adenocarcinomas, selective loss occurred in ovarian carcinoma cells from malignant effusions but not in primary tumors (Ferguson et al., 1985; Wang et al., 1991; Vegh et al., 1993) and down-regulation of HLA class I was not matched with histological types of ovarian adenocarcinomas.

The dominant role for the adaptive immune response in controlling metastasis is supported by the frequent loss of class I expression in vivo during lymph node metastasis in carcinomas of breast, colon, urinary bladder and kidney. As well as in melanomas (Lopez Nevot et al., 1986; Cordon-Cardo et al., 1991; Cromme et al., 1994). On the other hand, several reports have shown that an increase in expression of HLA class I results in a higher number of metastasis (Algarra et al., 1991) and restoration of HLA class I expression by $\gamma$ interferon treatment of melanoma cells reduces their metastatic potential (Zoller et al., 1988; Raval et al., 1998).

It is not clear whether HLA class II expression on tumor cells is a consequence of their malignant transformation or whether it is a correlate of an immunological process in which reactive lymphoid cells produce biological mediators that induce antigen expression (Ruiz-Cabello et al., 1991). Heterogeneous or focal expression of HLA class II antigens can occur on colon (Gutierrez et al., 1987), gastric tumors (Ma et al., 1994), and also on melanomas (Ruiter et al., 1991). These variations may be due to the heterogeneity of the tumor cell population, or the influence of the microenvironment.

Seven ovarian carcinomas examined failed to express $\mathrm{MHC}$ class II products regardless of histological type or clinical stage but stromal cells expressed the antigens strongly. However, not all histological categories of ovarian neoplasm were represented (Ferguson et al., 1985). It has also been reported that freshly isolated ovarian carcinoma cells from the ascitic fluid have a variable, although usually low, expression of HLA-DR antigens (Allavena et al., 1990). On the contrary, HLA class II was not found in normal ovarian surface epithelium, but can be detected in $44 \%$ of benign, and $43 \%$ of borderline and malignant epithelial ovarian tumors (Kabawat et al., 1983).

The studies on the altered expressions of HLA in ovarian cancers still have been lacking. Despite the potential clinical implications of these findings, this topic has been looked upon with some skepticism until recently because a number of early reports on the abnormal major histocompatibility complex phenotypes of tumor cells turned out to be technical artifacts (Hicklin et al., 1999).

Therefore we investigated whether immunohistochemically determined changes in class I and class II MHC expressions are related with tumorigenesis and tumor progression in human ovarian cancer tissues.

\section{Materials and Methods}

\section{Tumor specimens}

Paraffin-embedded tissue specimens were obtained from patients with malignant ovarian epithelial tumor who were treated at the Catholic University Medical Hospital from 1995 to 1998. Representative paraffin blocks from all primary tumors and regional lymph node metastases were selected and serially cut to $4-\mu \mathrm{m}$ sections. To ensure the presence of tumor, the first and last slide from each series were stained routinely with hematoxylineosin (H\&E) and subjected to microscopic examination. The number of the subjects was 5 cases of borderline serous malignancy of ovary, 20 cases of serous adenocarcinomas, 15 cases of borderline mucinous malignancy of ovary, and 10 cases of mucinous adenocarcinomas.

\section{Monoclonal antibodies}

The monoclonal antibody (mAb) L368 for $\beta 2 m$ of HLA class I, HC-10 for HLA-B, C heavy chains, and LGII612.14 for HLA class II heavy chain were used. L368 is a mouse $\operatorname{lgG}_{1}$ that recognizes $\beta 2 \mathrm{~m}, \mathrm{HC}-10$ is a mouse $\operatorname{lgG}_{2}$ that recognizes common epitope of HLA-B, C heavy chains, and LGII-612.14 is an antibody that recognizes the monomorphic determinant of $\beta$ chain of HLA-DR, -DQ, and -DP (Temponi et al., 1993). Monoclonal antibodies were kindly provided by Dr. Soldano Ferrone (Rosewell Park Cancer Institute, Buffalo, New York).

\section{Immunohistochemical staining (IHS)}

The avidin-biotin-peroxidase complex method (Hsu et al., 1981) was used. The paraffin-embedded tissues were dewaxed using xylene, treated with graded ethanol, rehydrated after removing paraffin and washed with water. Then, the tissues were placed in peroxide quenching solution made with hydrogen peroxide for $30 \mathrm{~min}$ to remove the endogenous peroxidase activity, treated with serum blocking solution (Zymed Laboratories, CA) for 30 min to block non-specific binding, treated with the primary antibody, left for overnight at $4^{\circ} \mathrm{C}$, washed with PBS, treated with the biotinylated secondary antibody (Zymed) for $30 \mathrm{~min}$, and washed with PBS. Then, the tissues were treated with an enzyme conjugate for 30 min, washed with PBS, treated with the aminoethyl carbazole (Zymed) as a chromogen for $18 \mathrm{~min}$. Then, the tissue sections were counterstained with hematoxylin.

\section{Analysis of HLA expression and statistics}

Ubiquitously present class I- or II-positive stromal cells (lymphocytes, fibroblasts, vascular endothelial cells, etc) and normal ovarian epithelium were used as intrinsic positive controls for the presence of class I or class II specificities in a given tissue and for the strength of the 
immunoreactivity of the mAb. The intensity of staining was evaluated semiquantitatively and divided into 4 grades as follows: ++, strong positive; +, moderately positive; \pm , weakly positive; - , negative. In case of heterogeneously stained tumors, corresponding tumor cell clusters were compared in the sequence of sections. If possible, we tried to make the reading to include one entire epithelial layer for normal ovarian epithelium and one entire layer for cancer tissues.

For the purpose of statistical analyses, the expression rates were converted into a 4-point system in which 1 point was given to $(-)$ reading, $2( \pm), 3(+)$ and $4(++)$ to examine changes in HLA expression patterns. In order to examine the changes by converting the rates of HLA expression into a 4-point system, the degrees of HLA expression were expressed in mean, median, and range between minimum and maximum values.

The relationship between the expression rate of HLA and histological type of the tissue was examined by Wilcoxon signed rank test and the differences amongst HLA expression patterns using each mAb were compared by Friedman test and Miller's nonparametric multiple comparison. $P$ values less than 0.05 were considered statistically significant. To compare the differences between primary and metastatic lesion by matched sample analysis, we excluded the non-metastatic cases.

\section{Results}

\section{HLA expressions in borderline serous malignancy (BSM)}

HLA class I and class II expression patterns in BSM of ovary were measured and compared with that in normal cells present in the same tissue sections (Table 1). Table 2 shows the degree of HLA expression expressed in mean, median and range of minimum to maximum value in each tissue. The result showed no significant down-regulation of HLA class I and class II heavy chain antigens in BSM tissues in comparison with those antigens in normal tissues.

\section{Changes in HLA expression patterns according to the progression of serous adenocarcinomas (SA)}

HLA class I and class II expression patterns in primary invasive ovarian carcinoma tissues and metastatic lesions were measured and compared with that in normal stromal tissues on the same tissue sections (Table 3). Table 4 shows the degree of HLA expression expressed in mean, median and range of minimum to maximum value in each tissue.

After determining the patterns of HLA expressions in primary and metastatic lesions of SA, the degrees of HLA expression of tumor tissues and corresponding normal stromal tissues were compared. According to Table 4 , in primary adenocarcinoma lesions, $\beta 2 \mathrm{~m}(P=$ $0.0313)$, HLA-B, C heavy chains $(P=0.0005)$ and class II heavy chain $(P=0.0001)$ expressions were all significantly down-regulated compared to their normal corresponding counterparts. Also, in metastatic lesions, HLA$B, C$ heavy chains $(P=0.0005)$ and class II heavy chain $(P=0.0156)$ expressions were all significantly downregulated compared to normal tissues. However, when the expression patterns in each tissue were compared between primary and metastatic lesions, no statistically significant difference was seen in class I and class II expression levels.

We also compared the down-regulation rates from normal stroma to tumor amongst three HLA classes in primary lesion by Friedman test, and the degree of down-regulation of $\beta 2 \mathrm{~m}$ showed somewhat lower than those of HLA-B, C heavy chains and HLA class II heavy chain $(P<0.05)$. But there was no significant differences between each two antigens (L368 vs. HC-10; L368 vs. LGII-612.14; HC-10 vs. LGII-612.14) by Miller's nonparametric multiple comparisons. However, in metastatic lesion, the degree of down-regulation from normal lymphoid cells to tumor in HLA-B, C heavy chains was

Table 1. Immunohistochemical staining patterns for HLA class I and class II in borderline serous malignancy of ovary

\begin{tabular}{cccccccc}
\hline & \multicolumn{3}{c}{$\beta 2 \mathrm{~m}$} & \multicolumn{2}{c}{$\begin{array}{c}\text { HLA-B, C } \\
\text { heavy chain } \\
\text { Borderline }\end{array}$} & $\begin{array}{c}\text { Class II heavy } \\
\text { chain } \\
\text { Borderline }\end{array}$ \\
\hline \multicolumn{7}{c}{ Batient } \\
\hline 1 & Ib & \pm & \pm & \pm & \pm & \pm & \pm \\
2 & lb & \pm & \pm & - & \pm & ++ & ++ \\
3 & la & \pm & \pm & \pm & \pm & - & \pm \\
4 & la & \pm & \pm & \pm & \pm & + & + \\
5 & Illc & \pm & \pm & + & + & ++ & ++ \\
\hline
\end{tabular}

Semiquantitative evaluation of immunoreactivity of normal and tumor cells are described in Materials and Methods.

Table 2. HLA class I and class II expressions in 5 patients with borderline serous malignancy of ovary

\begin{tabular}{|c|c|c|c|c|c|c|c|c|c|c|c|c|}
\hline \multirow[b]{2}{*}{$\begin{array}{l}\text { Report } \\
\text { Tumor }\end{array}$} & \multirow[b]{2}{*}{$\begin{array}{c}\text { No. } \\
5\end{array}$} & \multicolumn{3}{|c|}{$\beta 2 m$} & \multicolumn{4}{|c|}{ HLA-B, C heavy chain } & \multirow[b]{2}{*}{$\begin{array}{c}\text { No. } \\
5\end{array}$} & \multicolumn{3}{|c|}{ Class II heavy chain } \\
\hline & & $\begin{array}{c}\text { Mean } \\
2.0\end{array}$ & $\begin{array}{l}\text { Median } \\
2\end{array}$ & $\begin{array}{c}\text { Range } \\
2-2\end{array}$ & $\begin{array}{c}\text { No. } \\
5\end{array}$ & $\begin{array}{c}\text { Mean } \\
2.0\end{array}$ & $\begin{array}{l}\text { Median } \\
2\end{array}$ & $\begin{array}{c}\text { Range } \\
1-3\end{array}$ & & $\begin{array}{c}\text { Mean } \\
2.8\end{array}$ & $\begin{array}{c}\text { Median } \\
3\end{array}$ & $\begin{array}{c}\text { Range } \\
1-4\end{array}$ \\
\hline Stroma & 5 & 2.0 & 2 & $2-2$ & 5 & 2.2 & 2 & $2-3$ & 5 & 3.0 & 3 & $2-4$ \\
\hline
\end{tabular}


Table 3. Immunohistochemical staining patterns for HLA class I and class II in serous adenocarcinoma of ovary

\begin{tabular}{|c|c|c|c|c|c|c|c|c|c|c|c|c|c|}
\hline \multirow[b]{3}{*}{ Patient } & \multirow[b]{3}{*}{ Stage } & \multicolumn{4}{|c|}{$\beta 2 m$} & \multicolumn{4}{|c|}{ HLA-B, C heavy chain } & \multicolumn{4}{|c|}{ Class II heavy chain } \\
\hline & & \multicolumn{2}{|c|}{ Primary } & \multicolumn{2}{|c|}{ Metastasis } & \multicolumn{2}{|c|}{ Primary } & \multicolumn{2}{|c|}{ Metastasis } & \multicolumn{2}{|c|}{ Primary } & \multicolumn{2}{|c|}{ Metastasis } \\
\hline & & Tumor & Stroma & Tumor & Stroma & Tumor & Stroma & Tumor & Stroma & Tumor & Stroma & Tumor & Stroma \\
\hline \multirow[t]{2}{*}{1} & IIIC & \pm & \pm & \pm & \pm & \pm & ++ & - & ++ & \pm & ++ & - & ++ \\
\hline & & & & & & \pm & + & & & \pm & + & & \\
\hline \multirow[t]{2}{*}{2} & IIIC & ++ & ++ & + & + & - & ++ & \pm & ++ & - & ++ & \pm & \pm \\
\hline & & & & & & ++ & ++ & & & + & ++ & & \\
\hline 3 & IIIC & + & + & ++ & ++ & ++ & ++ & ++ & ++ & ++ & ++ & ++ & ++ \\
\hline 4 & IIIC & \pm & \pm & \pm & \pm & + & ++ & + & ++ & + & ++ & + & + \\
\hline 5 & IIIC & + & + & + & + & - & + & ++ & ++ & + & ++ & ++ & ++ \\
\hline 6 & IIIC & + & + & + & + & \pm & ++ & - & ++ & \pm & ++ & \pm & ++ \\
\hline \multirow[t]{2}{*}{7} & Ic & \pm & \pm & \pm & \pm & ++ & ++ & \pm & ++ & \pm & ++ & ++ & ++ \\
\hline & & - & \pm & & & \pm & ++ & & & \pm & + & & \\
\hline \multirow[t]{2}{*}{8} & lib & \pm & + & - & \pm & \pm & + & ++ & ++ & + & ++ & + & ++ \\
\hline & & \pm & + & & & + & ++ & & & + & ++ & & \\
\hline \multirow[t]{2}{*}{9} & IIIC & \pm & + & + & + & ++ & ++ & ++ & ++ & ++ & ++ & ++ & ++ \\
\hline & & + & + & & & ++ & ++ & & & + & + & & \\
\hline 10 & Ic & \pm & \pm & - & \pm & + & + & - & \pm & ++ & ++ & \pm & ++ \\
\hline 11 & IIIC & \pm & \pm & - & \pm & & & - & \pm & ++ & ++ & \pm & ++ \\
\hline 12 & IIIc & \pm & \pm & \pm & \pm & \pm & ++ & - & ++ & \pm & ++ & - & ++ \\
\hline 13 & Illc & ++ & ++ & + & + & ++ & ++ & \pm & ++ & + & ++ & \pm & \pm \\
\hline 14 & IIlc & + & + & + & + & \pm & + & - & ++ & \pm & ++ & \pm & ++ \\
\hline 15 & Ic & \pm & \pm & \pm & \pm & ++ & ++ & \pm & ++ & \pm & ++ & ++ & ++ \\
\hline 16 & IIIC & - & \pm & \pm & \pm & \pm & ++ & \pm & ++ & \pm & + & ++ & ++ \\
\hline \multirow[t]{2}{*}{17} & la & \pm & \pm & $\mathrm{N}^{*}$ & $\mathrm{~N}$ & \pm & \pm & $\mathrm{N}$ & $\mathrm{N}$ & + & + & $\mathrm{N}$ & $\mathrm{N}$ \\
\hline & & \pm & \pm & $\mathrm{N}$ & $\mathrm{N}$ & + & ++ & $\mathrm{N}$ & $\mathrm{N}$ & + & ++ & $\mathrm{N}$ & $\mathrm{N}$ \\
\hline \multirow[t]{2}{*}{18} & IIIC & \pm & \pm & $\mathrm{N}$ & $\mathrm{N}$ & + & + & $\mathrm{N}$ & $\mathrm{N}$ & + & ++ & $\mathrm{N}$ & $\mathrm{N}$ \\
\hline & & \pm & \pm & $\mathrm{N}$ & $\mathrm{N}$ & \pm & \pm & $\mathrm{N}$ & $\mathrm{N}$ & \pm & ++ & $\mathrm{N}$ & $\mathrm{N}$ \\
\hline 19 & $\mathrm{Ib}$ & + & ++ & $\mathrm{N}$ & $\mathrm{N}$ & ++ & ++ & $\mathrm{N}$ & $\mathrm{N}$ & + & ++ & $\mathrm{N}$ & $\mathrm{N}$ \\
\hline \multirow[t]{2}{*}{20} & Ic & \pm & + & $\mathrm{N}$ & $\mathrm{N}$ & - & + & $\mathrm{N}$ & $\mathrm{N}$ & - & + & $\mathrm{N}$ & $\mathrm{N}$ \\
\hline & & + & ++ & $\mathrm{N}$ & $\mathrm{N}$ & ++ & ++ & $\mathrm{N}$ & $\mathrm{N}$ & ++ & ++ & $\mathrm{N}$ & $\mathrm{N}$ \\
\hline
\end{tabular}

${ }^{*}$ no metastasis

Table 4. HLA class I and class II expressions in 20 patients with serous adenocarcinoma of ovary

\begin{tabular}{|c|c|c|c|c|c|c|c|c|c|c|c|c|}
\hline \multirow[b]{2}{*}{ Report } & \multirow[b]{2}{*}{ No. } & \multicolumn{3}{|c|}{$\beta 2 \mathrm{~m}$} & \multirow[b]{2}{*}{ No. } & \multicolumn{3}{|c|}{ HLA-B, C heavy chain } & \multirow[b]{2}{*}{ No. } & \multicolumn{3}{|c|}{ Class II heavy chain } \\
\hline & & Mean & Median & Range & & Mean & Median & Range & & Mean & Median & Range \\
\hline \multicolumn{13}{|l|}{ Primary } \\
\hline Tumor & 20 & $2.4^{*}$ & 2 & $1-4$ & 20 & $2.8^{*}$ & 2.5 & $1-4$ & 20 & $2.7^{*}$ & 2.75 & $2-4$ \\
\hline Stroma & 20 & 2.7 & 2.5 & $2-4$ & 20 & 3.6 & 4 & $2.5-4$ & 20 & 3.8 & 4 & $3-4$ \\
\hline \multicolumn{13}{|c|}{ Metastasis } \\
\hline Tumor & 16 & 2.4 & 2 & $1-4$ & 16 & $2.2^{*} \dagger$ & 2 & $1-4$ & 16 & $2.8^{*}$ & 2.5 & $1-4$ \\
\hline Stroma & 16 & 2.5 & 2 & $2-4$ & 16 & 3.8 & 4 & $2-4$ & 16 & 3.7 & 4 & $2-4$ \\
\hline
\end{tabular}

*denotes significant difference between tumor and normal stroma in each lesion by Wilcoxons signed rank test $(P<0.01)$.

tdenotes significant difference of the down-regulation rates from normal stroma to tumor compared to L368 in each lesion by Friedman test and Miller's nonparametric multiple comparison $(P<0.05)$.

significantly higher than that of $\beta 2 \mathrm{~m}(P<0.05)$.

Figure 1 shows staining patterns of primary tumor and metastatic lymph node of serous adenocarcinoma of ovary. Primary tumor tissue with mAb against HLA-B, C heavy chain (Figure $1 \mathrm{~A}$ ) show weakly positive intensity of expression as compared with normal tissues. Expre- ssion patterns for mAb against HLA-B, $C$ heavy chain in metastatic lymph node tissues (Figure 1B) were similar to primary lesions. The staining results of primary tumor (Figure 1C) and metastatic lymph node tissues (Figure 1D) using class II heavy chain mAb were also similar to those of HLA-B, C heavy chain mAb. 


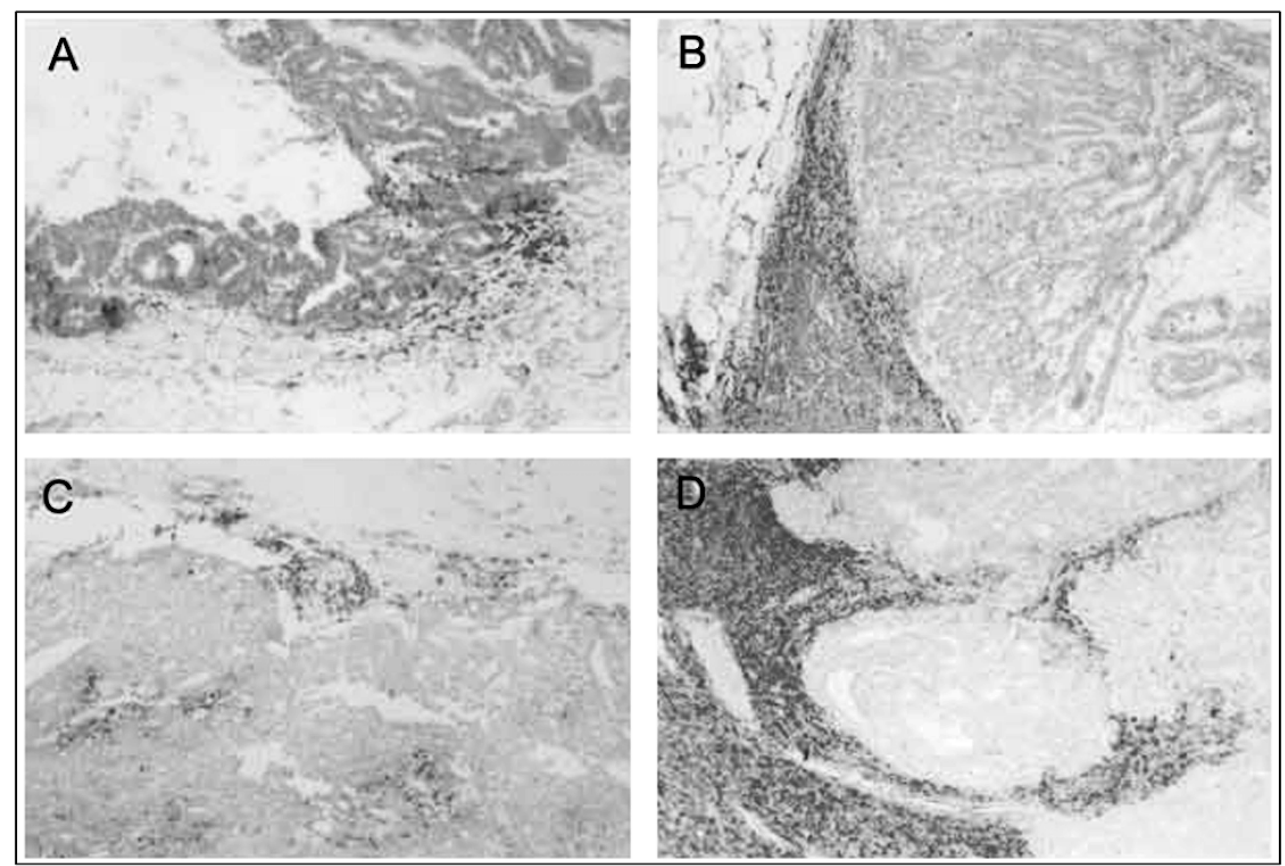

Figure 1. Immunohistochemical staining for HLA class I and class II in primary and metastatic serous adenocarcinoma of ovary. (A) HLA class I staining in the primary tumor tissue showing strongly positive reaction in the normal stromal and infiltrating lymphoid cells surrounding the tumor cells. In contrast, the tumor cells show weakly positive staining. (B) HLA class I staining in the metastatic adenocarcinoma of pelvic lymph node showing strongly positive intensity in the normal lymphoid cells and negative expression in the metastatic tumor cells. (C) HLA class II stain in the primary tumor showing strongly positive intensity in the normal stromal and infiltrating lymphoid cells surrounding the tumor cells. Most tumor cells show negative intensity of expression but focally positive intensity. (D) HLA class II stain in the metastatic carcinoma showing strongly positive intensity in the normal lymphoid cells. But the metastatic tumor cell nest shows mostly negative but focally weakly positive intensity of expression. (Magnification $\times 100$ ).

\section{HLA expressions in borderline mucinous malignancy (BNMM)}

HLA class I and class II expression patterns in BMM were measured and compared with that in normal tissues on the same tissue sections (Table 5). Table 6 shows the degree of HLA expression expressed in mean, median and range of minimum to maximum value in each tissue. There were no differences in $\beta 2 \mathrm{~m}$ and HLA-B, C. Heavychain expression levels between borderline lesions and normal tissues. But, in BMM, HLA class II heavy chain antigen expressions were significantly down-regulated compared to normal tissues $(P=0.0002)$.

Degrees of down-regulation from normal stroma to tumor were compared amongst three antigens using Friedman test and Miller's nonparametric comparison, and the down-regulation rate in LGII-612.14 showed significantly higher than those in L368 and HC-10 $(P<$ 0.05 ). Figure 2 shows staining patterns of normal tissues and BMM lesion with mAb against class II heavy chain. Borderline lesions show weakly positive intensity of expression as compared with normal tissues. Surrounding normal stromal cells show strongly positive intensity.

HLA expressions in mucinous adenocarcinomas (BA) HLA class I and class II expression patterns in MA were
Table 5. Immunohistochemical staining patterns for HLA class I and class II in borderline mucinous malignancy of ovary

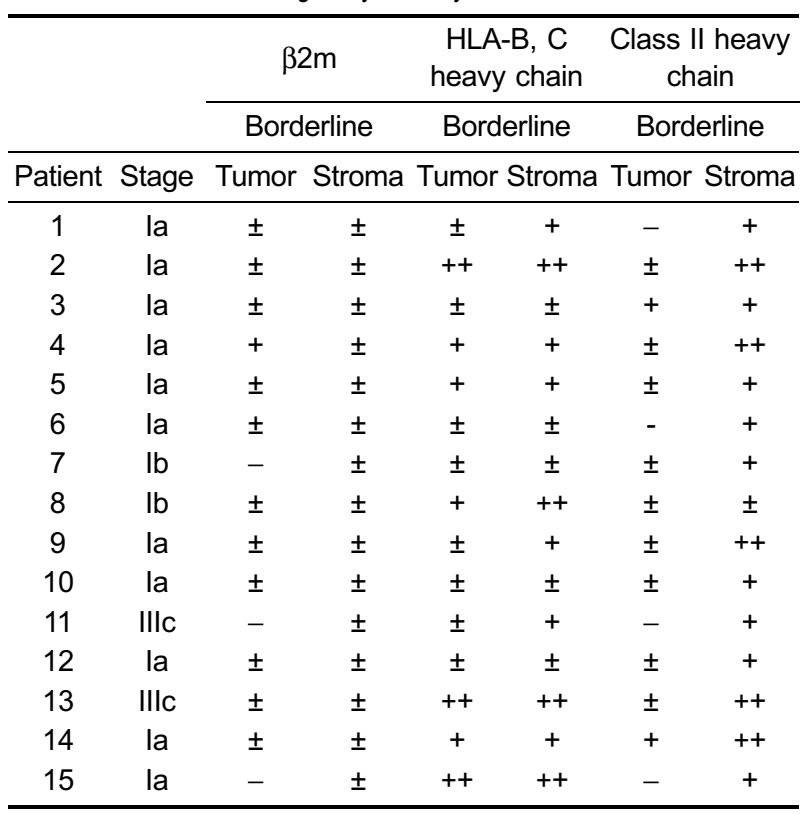

measured and compared with that in normal tissues on the same tissue sections (Table 7). Table 8 shows the 
Table 6. HLA class I and class II expressions in 15 patients with borderline mucinous malignancy of ovary

\begin{tabular}{|c|c|c|c|c|c|c|c|c|c|c|c|c|}
\hline \multirow[b]{2}{*}{ Report } & \multirow[b]{2}{*}{ No. } & \multicolumn{3}{|c|}{$\beta 2 m$} & \multicolumn{4}{|c|}{ HLA-B, C heavy chain } & \multirow[b]{2}{*}{ No. } & \multicolumn{3}{|c|}{ Class II heavy chain } \\
\hline & & Mean & Median & Range & No. & Mean & Median & Range & & Mean & Median & Range \\
\hline Tumor & 15 & $1.9^{\dagger}$ & 2 & $1-3$ & 15 & $2.7^{\dagger}$ & 2 & $2-4$ & 15 & $1.9^{*}$ & 2 & $1-3$ \\
\hline Stroma & 15 & 2 & 2 & $2-2$ & 15 & 2.9 & 3 & $2-4$ & 15 & 3.3 & 3 & $2-4$ \\
\hline
\end{tabular}

$P$-value; comparing the difference among three tissues in each class by Friedman test.

*denotes significant difference compared to normal stroma by Wilcoxon's signed rank test $(P<0.05)$.

'denotes significant difference compared to LGII-612.14 in the degree of down-regulation from normal stroma by Friedman test and Miller's nonparametric multiple comparison $(P<0.05)$.

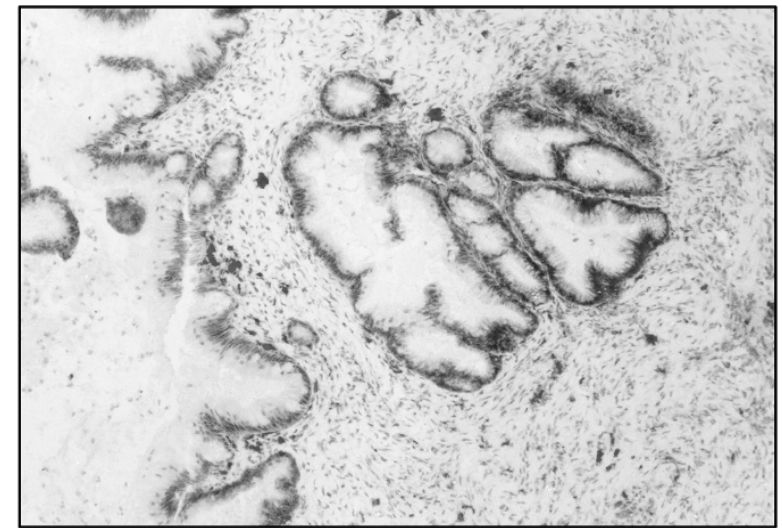

Figure 2. Immunohistochemical staining of borderline mucinous malignancy of ovary. The tumor cells show focally weakly positive intensity of expression and normal stromal tissue surrounding the tumor cells shows strongly positive intensity of expression. (Magnification $\times 100$ ). Monoclonal antibody against HLA class II heavy chain was used.

degree of HLA expression expressed in mean, median and range of minimum to maximum value in each tissue. There were significant differences in $\beta 2 \mathrm{~m}(P=0.0313)$, HLA-B, C heavy chains $(P=0.0020)$ and class II heavy chain $(P=0.0313)$ expression levels between normal and tumor tissues. However, there were no significant differences among HLA classes in the degree of downregulation from normal stroma to tumor in MA of ovary. The tumor cells show negative intensity of expression and the normal stromal tissue shows strongly positive intensity of expression (Figure 3).

\section{Discussion}

Virtually all benign and premalignant lesions analysed
Table 7. Immunohistochemical staining patterns for HLA class I and class II in mucinous adenocarcinoma of ovary

\begin{tabular}{|c|c|c|c|c|c|c|c|}
\hline & \multicolumn{2}{|c|}{$\beta 2 m$} & \multicolumn{2}{|c|}{$\begin{array}{c}\mathrm{HLA}-\mathrm{B}, \mathrm{C} \\
\text { heavy chain }\end{array}$} & \multicolumn{2}{|c|}{$\begin{array}{c}\text { Class II heavy } \\
\text { chain }\end{array}$} \\
\hline & & \multicolumn{2}{|c|}{ Primary } & \multicolumn{2}{|c|}{ Primary } & \multicolumn{2}{|c|}{ Primary } \\
\hline Patient & Stage & Tumor & Stroma & Tumor & Stroma & Tumor & Stroma \\
\hline 1 & IC & \pm & \pm & + & ++ & + & + \\
\hline 2 & Ic & \pm & \pm & \pm & + & + & + \\
\hline 3 & la & - & \pm & + & ++ & + & ++ \\
\hline 4 & Ic & - & \pm & + & ++ & + & ++ \\
\hline 5 & Ic & \pm & + & + & ++ & + & ++ \\
\hline 6 & la & - & \pm & + & ++ & + & ++ \\
\hline 7 & Ic & \pm & + & + & ++ & + & + \\
\hline 8 & la & \pm & + & \pm & + & + & ++ \\
\hline 9 & lib & \pm & \pm & - & \pm & + & + \\
\hline 10 & Ic & \pm & \pm & + & ++ & + & ++ \\
\hline
\end{tabular}

from breast, colon, cervix and larynx epithelia are HLA class I positive (Garrido et al., 1993). Despite other genetic and morphological changes at this stage of tumor development, the expression of HLA class I antigens is apparently not altered (Hilders et al., 1994). However, the molecular basis of the under-expression of class I $\mathrm{MHC}$ antigens in tumor cells still remains unclear. Very few studies analyze the mechanisms responsible for such alterations (Redondo et al., 1997). It has been reported that among the neoplasms examined, all benign epithelial tumors, $86 \%$ of borderline and $81 \%$ of malignant epithelial tumors reacted with anti-HLA and /or $\beta 2 \mathrm{~m}$ antibodies (Kabawat et al., 1983). We demonstrated that in borderline malignancy of ovary, the distribution and intensity of $\beta 2 \mathrm{~m}$ and HLA-B, C heavy chain expressions just failed to reach statistical significance.

Table 8. HLA class I and class II expressions in 5 patients with mucinous adenocarcinoma of ovary

\begin{tabular}{|c|c|c|c|c|c|c|c|c|c|c|c|c|}
\hline \multirow[b]{2}{*}{ Report } & \multirow[b]{2}{*}{$\mathrm{N}$} & \multicolumn{3}{|c|}{$\beta 2 m$} & \multirow[b]{2}{*}{$\mathrm{N}$} & \multicolumn{3}{|c|}{ HLA-B, C heavy chain } & \multirow[b]{2}{*}{$\mathrm{N}$} & \multicolumn{3}{|c|}{ Class II heavy chain } \\
\hline & & Mean & Median & Range & & Mean & Median & Range & & Mean & Median & Range \\
\hline \multicolumn{13}{|l|}{ Primary } \\
\hline Tumor & 10 & $1.7^{*}$ & 2 & $1-2$ & 10 & $2.6^{*}$ & 3 & $1-3$ & 10 & $3^{*}$ & 3 & $3-3$ \\
\hline Stroma & 10 & 2.3 & 2 & $2-3$ & 10 & 3.6 & 4 & $2-4$ & 10 & 3.6 & 4 & $3-4$ \\
\hline
\end{tabular}

*denotes significant difference compared to normal stroma in each lesion by Wilcoxon's signed rank test. $(P<0.05)$ 


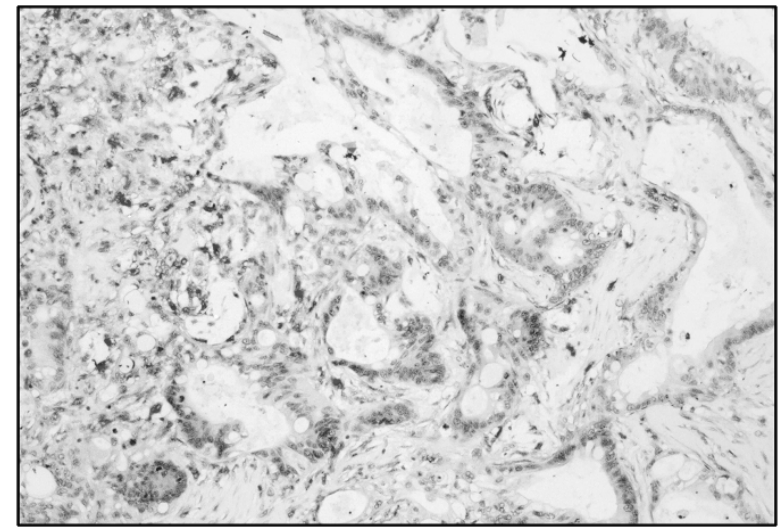

Figure 3. Immunohistochemical staining of mucinous adenocarcinoma of ovary. The tumor cells show negative intensity of expression. The normal stromal and lymphoid tissue surrounding the tumor cells shows strongly positive intensity of expression. (Magnification $\times 200$ ). Monoclonal antibody against HLA class II heavy chain was used.

But, in adenocarcinoma of ovary, $\beta 2 \mathrm{~m}$, HLA-B, C heavy chain and class II antigen expressions were downregulated or decreased compared with normal stromal tissues. These results suggest that the down-regulation of HLA class I antigen is an important mechanism of invasiveness of ovarian cancers.

Cancer is a multistep process often characterized by the accumulation of multiple genetic events and the interaction with the surrounding tissues of the particular target cell. Therefore, it could be expected that malignant potential in the metastatic site is more variable and heterogeneous than that in the primary site. Some investigators showed a significant increase in the prevalence of HLA-A and HLA-B, C down-regulation in metastasized neoplastic cells as compared with the primary tumor (Cromme et al., 1994; Kaklamanis et al., 1995). The frequency of HLA class I down-regulation in metastases differs among various types of cancer (37$69 \%$ ), although to a lesser extent than that in primary lesions (Hicklin et al., 1999). In all types of tumors analyzed, the frequency of HLA class I down-regulation is higher in metastases than in primary lesions. Recent study on squamous cell carcinoma of the uterine cervix also revealed that significant down-regulation of HLA class I antigen in metastatic lesions in compared with primary tumors (Ryu et al., 2001). Selective loss of HLA class I antigen in ovarian carcinoma cells collected from malignant effusion (12 of 22, 54\%) was observed but not in 7 primary tumors (Vegh et al., 1993). Their experiments showed that selective defects in the expression of HLA class I alleles in ovarian and lung carcinomas are rather frequent and they can involve several HLA loci. On the contrary, it has been reported that the presence of metastasis did not relate to the expression of MHC antigens (Vanky et al., 1988). These findings suggest that functional abnormalities of HLA or other genetic mutation are associated with the metastases of ovarian cancer. In our study, only HLA-B, C heavy chain expressions were down-regulated in metastatic SA, but there were no differences in HLA class I antigen expression level between primary and metastatic tumors.

HLA class II antigens are not normally expressed in most epithelia but rather appear under different pathological circumstances including inflammation, tumor transformation and autoimmunity (Garrido et al., 1993). However, epithelia in breast, stomach and lung tissues are constitutively weakly HLA-DR+. The majority of tissues, with the exception of areas of the gastric and respiratory tract, do not express HLA class II antigens. Under some circumstances, originally HLA class II negative cell types can express class II molecules. HLA-DR expression is induced on the luteinizing granulosa cells during the course of corpus luteum formation in ovary (Fujiwara et al., 1993). MHC class II products were also detectable on endothelial and follicle lining cells but absent from epithelial and connective tissue (Ferguson et al., 1985).

It is not clear whether HLA class II expression on tumor cells is a consequence of their malignant transformation. Altogether, little is known about the effect of HLA class II on the tumor cells (Ruiz-Cabello et al., 1991). In colon, cervix, larynx and breast tissues, the majority of premalignant lesions acquire de novo expression or increase in their HLA class II expression (Garrido et al., 1993). In malignant melanoma, expression of HLADR antigens is correlated with a more aggressive phenotype and a higher risk of metastasis particularly in the absence of DP, DQ or HLA-ABC (Ruiz-Cabello et al., 1991; Garrido et al., 1993). The possible explanation for this is that high DR expression in early disease is able to function and present antigen normally while high DR in metastatic disease is mutated so it is unable to present antigen (Concha et al., 1995).

Some investigators demonstrated that ovarian cancers failed to express MHC class II products regardless of histological type or clinical stage but stromal cells expressed the antigens strongly. On the contrary, ovarian cancers expressed DR antigens where none were detectable in normal epithelium (Ferguson et al., 1985). Although the intensity of expression was not measured quantitatively, HLA class II was not found in normal ovarian surface epithelium, the antigen could be detected in $44 \%$ of benign, and $43 \%$ of borderline and malignant epithelial ovarian tumors (Kabawat et al., 1983). In contrast with previous studies, our present study shows that HLA class II molecules are widely distributed on normal ovarian tissues and HLA class II heavy chain antigen expressions were down-regulated in borderline mucinous malignancies.

In this study, in SA and MA, the distribution and intensity of HLA class II expressions in tumor were downregulated compared with normal stromal tissues with statistical significance. In metastatic cancer of ovary, the 
expressions of HLA class II antigens were not downregulated compared with primary tumor. This result was in contrast with previous study on cervical carcinoma where HLA class II antigens were down regulated in metastatic lesions compared with primary tumor (Ryu et al., 2001). Thus, we could distinguish the reduction or absence of HLA class II molecule expression was not related to metastatic potential in ovarian cancer.

Although we can not explain how HLA class II molecules are widely distributed on normal ovarian tissues exactly, but, they might reflect de novo expressions of HLA class II which was influenced by cancer or inadequate sensitivity of immunohistochemical staining. Our data shows decreased expressions of HLA class II in ovarian cancers in comparison with normal tissue. These findings suggest cancer cells increase aggressiveness by decreasing their expressions of HLA class II. In metastatic cancer of ovary, the expressions of HLA class II antigens were not down-regulated compared with primary tumor. This agrees with the work of Vanky et al. (1988). In adenocarcinomas of ovary, $\beta 2 \mathrm{~m}$, HLA$B, C$ heavy chain and class II antigen expressions were down-regulated or decreased compared with normal stromal tissues. These results suggest that the downregulation of HLA antigen is an important mechanism of malignant transformation of ovarian cancers. In metastatic cancers of ovary, the expressions of $\beta 2 \mathrm{~m}$, HLA-B, $C$ heavy chain and class II antigens were not downregulated compared with primary tumors. These findings suggest that other mechanisms are associated with the metastases of ovarian cancer.

Further studies using more tissue samples and comparing clinical variables are needed to determine whether HLA class I and class II antigen expression could be used as a clinical marker of tumor malignancy or metastasis in ovarian cancers.

\section{References}

Algarra I, Gaforio JJ, Garrido A, Mialdea MJ, Perez M, Garrido F. Heterogeneity of MHC-class-I antigens in clones of methylcholanthrene-induced tumors. Implications for local growth and metastasis. Int J Cancer 1991;6:73-81

Allavena P, Peccatori F, Maggioni D, Erroi A, Sironi M, Colombo N, Lissoni A, Galazka A, Meiers W, Mangioni C, Mantovani A. Intraperitoneal recombinant $\gamma$-interferon in patients with recurrent ascitic ovarian carcinoma: modulation of cytotoxicity and cytokine production in tumor-associated effectors and of major histocompatibility antigen expression on tumor cells. Cancer Res 1990;50:7318-23

Browning M, Dunnion D. HLA and cancer: implications for cancer immunotherapy and vaccination. Eur $\mathrm{J}$ Immunogenet 1997;24:293-12

Campbell RD, Trowsdale J. Map of the human MHC. Immunol Today 1993;14:349-52
Concha A, Ruiz-Cabello F, Cabrera T, Nogales F, Collado A, Garrido F. Different patterns of HLA DR antigen expression in normal epithelium, hyperplastic and neoplastic malignant lesions of the breast. Eur J Immunogenet 1995;22:299-10

Cordon-Cardo C, Fuks Z, Drobnjak M, Moreno C, Eisenbach L, Feldman M. Expression of HLA-A,B,C antigens on primary and metastatic tumor cell populations of human carcinomas. Cancer Res 1991;51:6372-80

Cromme FV, Bommel PFJ, Walboomers JMM, Gallee MPW, Stern PL, Kenemans P, Helmerhorst TJM, Stukart MJ, Meijer CJLM. Differences in MHC and TAP-1 expression in cervical cancer lymph node metastases as compared with the primary tumours. Br J Cancer 1994;69:1176-81

Ferguson A, Moore M, Fox H. Expression of MHC products and leukocyte differentiation antigens in gynaecological neoplasms: An immunohistological analysis of the tumor cells and infiltrating leukocytes. Brit J Cancer 1985;52:551-63

Fujiwara H, Ueda M, Imai K, Fukuoka M, Yasuda K, Takakura $\mathrm{K}$, Suginami H, Kanzaki H, Inoko H, Mori T. Human leukocyte antigen-DR is a differentiation antigen for human granulosa cells. Biol Reprod 1993;49:705-15

Garrido F, Cabrera T, Concha A, Glew S, Ruiz-Cabello F, Stern PL. Natural history of HLA expression during tumor development. Immunol Today 1993;14:491-99

Garrido F, Cabrera T, Lopez-Nevot MA, Ruiz-Cabello F. HLA class I antigens in human tumors. Adv Cancer Res 1995;67: 155-95

Garrido F, Ruiz-Cabello F, Cabrera T, Perez-Villar JJ, LopezBotet M, Duggan-Keen M, Stern PL. Implications for immunosurveillance of altered HLA class I phenotypes in human tumours. Immunol Today 1997;18:89-95

Gutierrez J, Lopez-Nevot MA, Cabrera T, Oliva R, Esquivias J, Ruiz-Cabello F, Garrido F. Class I and II HLA antigen distribution in normal mucosa, adenoma and colon carcinoma: relation with malignancy and invasiveness. Exp Clin Immunogenet 1987;4:144-52

Hicklin D, Marincola FM, Ferrone S. HLA class I antigen downregulation in human cancers: T-cell immunotherapy revives an old story. Mol Med Today 1999;5:178-86

Hilders CG, Houbiers JG, Krul EJ, Fleuren GJ. The expression of histocompatibility-related leukocyte antigens in the pathway to cervical carcinoma. Am J Clin Pathol 1994;101:512

Howard MC, Spack EG, Choudhury K, Greten TF, Schneck JP. MHC-based diagnostics and therapeutics. Immunol Today 1999;20:161-65

Hsu SM, Raine L, Fanger $\mathrm{H}$. The use of avidin-biotinperoxidase complex $(A B C)$ in immunoperoxidase technique: $A$ comparison between $\mathrm{ABC}$ and unlabeled antibody (PAP) procedures. Histochem Cytochem 1981;29:577-80

Kabawat SE, Bast RC, Welch WR, Knapp RC, Bhan AK. Expression of major histocompatibility antigens and nature of inflammatory cellular infiltrate in ovarian neoplasms. Int J Cancer 1983;32:547-54

Kaklamanis L, Leek R, Koukourakis M, Gatter KC, Harris AL. 
Loss of transporter in antigen processing 1 transport protein and major histocompatibility complex class I molecules in metastatic versus primary breast cancer. Cancer Res 1995; 55:5191-94

Koopman LA, Mulder A, Corver WE, Anholts JD, Giphart MJ, Claas FH, Fleuren GJ. HLA class I phenotype and genotype alterations in cervical carcinomas and derivative cell lines. Tissue Antigens 1998;51:623-36

Lopez Nevot MA, Garcia E, Pareja E, Bonal FJ, Martin J, Ruiz-Cabello F, Serrano S, Garrido F. Differential expression of HLA class I and II antigens in primary and metastatic melanomas. J Immunogenet 1986;13: 219-27

Ma XC, Hattori T, Kushima R, Terata N, Kodama M. Expression of HLA-class II antigen in gastric carcinomas. Its relationship to histopathological grade, lymphocyte infiltration and five-year survival rate. Acta Oncol 1994;33:187-90

Powis SJ, Deverson EV, Coadwell WJ, Ciruela A, Huskisson NS, Smith H, Butcher GW, Howard JC. Effect of polymorphism of an MHC-linked transporter on the peptides assembled in a class I molecule. Nature 1992;357:211-15

Raval A, Puri N, Rath PC, Saxena RK. Cytokine regulation of expression of class I MHC antigens. Exp Mol Med 1998;30:113

Redondo M, Concha A, Ruiz-Cabello F, Morell M, Esteban F, Talavera P, Garrido F. Class I major histocompatibility complex antigens and tumor ploidy in breast and bronchogenic carcinomas. Cancer Detect Prev 1997;21:22-28

Ruiter DJ, Mattijssen V, Broecker EB, Ferrone S. MHC antigens in human melanomas. Semin Cancer Biol 1991;2: 35-45

Ruiz-Cabello F, Klein E, Garrido F. MHC antigens on human tumor. Immunol Lett 1991;29:181-90
Ryu KS, Lee YS, Kim BK, Park YG, Kim YW, Hur SY, Kim TE, Kim I-K, Kim JW. Alterations of HLA class I and II antigen expression in preinvasive, invasive and metastatic cervical cancers. Exp Mol Med 2001:33:136-44

Schrier PI, Bernards R, Vaessen RT, Houweling A, van der Eb AJ. Expression of class I major histocompatibility antigens switched off by highly oncogenic adenovirus 12 in transformed rat cells. Nature 1983;305:771-75

Temponi M, Kekish U, Hamby CV, Nielsen H, Marboe CC, Ferrone S. Characterization of anti-HLA class II monoclonal antibody LGII-612.14 reacting with formalin fixed tissues. J Immunol Methods 1993;161:239-56

Townsend A, Ohlen C, Bastin J, Ljunggren HG, Foster L, Karre K. Association of class I major histocompatibility heavy and light chains induced by viral peptides. Nature 1989;340: 443-48

Vanky F, Stuber G, Willems J, Sjowall K, Larsson B, Book K, Ivert $\mathrm{T}$, Peterffy $\mathrm{A}$, Klein $\mathrm{E}$. Importance of $\mathrm{MHC}$ antigen expression on solid tumors in the in vitro interaction with autologous blood lymphocytes. Cancer Immunol Immun 1988; 27:213-22

Vegh Z, Wang P, Vanky F, Klein E. Selectively down-regulated expression of major histocompatibility complex class I alleles in human solid tumors. Cancer Res 1993;53:2416-20

Wang P, Vanky F, Klein E. Application of isoelectric focusing for studies of major histocompatibility complex class I antigen expression on human carcinomas and sarcomas. Cancer Immunol Immun 1991;33:65-69

Zoller M, Strubel A, Hammerling G, Andrighetto G, Raz A, Ben-Ze'ev A. Interferon-gamma treatment of B16 melanoma cells: opposing effects for non-adaptive and adaptive immune defense and its reflection by metastatic spread. Int J Cancer 1988;41:256-66 